\title{
Community-managed Health Programs for Better Health Outcomes: Preliminary Results of a Community Participatory Research in Murcia and Isabel, Negros Occidental, Philippines
}

\author{
Hilton Y. Lam, ${ }^{1}$ Isidro C. Sia, ${ }^{2}$ Jaifred Christian F. Lopez, ${ }^{3,4}$ Ruben N. Caragay, ${ }^{5}$ \\ Leonardo R. Estacio, Jr., ${ }^{6}$ Edna Estifania A. Co, ${ }^{7}$ Jennifer S. Madamba, ${ }^{8}$ \\ Regina Isabel B. Abola, ${ }^{1}$ Charlyn M. Maybituin ${ }^{1}$ and Dulce Corazon Velasco 9 \\ ${ }^{1}$ Institute of Health Policy and Development Studies, National Institutes of Health, University of the Philippines Manila \\ ${ }^{2}$ College of Medicine, University of the Philippines Manila \\ ${ }^{3}$ Office of Research and Innovation, and College of Medicine, San Beda University Manila \\ ${ }^{4}$ Tambalista, Inc., Quezon City, Philippines \\ ${ }^{5}$ College of Medicine, Bicol University, Albay \\ ${ }^{6}$ College of Arts and Sciences, University of the Philippines Manila \\ ${ }^{7}$ Center for Integrative and Development Studies, University of the Philippines Diliman, Quezon City \\ ${ }^{8}$ Emerging Interdisciplinary Research, University of the Philippines System \\ ${ }^{9}$ Integrative Medicine for Alternative Healthcare Systems (INAM) Philippines, Inc., Quezon City
}

\begin{abstract}
Background. Community-managed health programs (CMHPs) were designed to promote community selfdetermination in addressing health needs, but there is a need to evaluate how CMHPs can lead to better outcomes while accommodating changes in the national health system, which requires analysis of current CMHP interventions, institutional and community readiness, and points of interface with other health facilities.

Objective and Methods. This preliminary study aimed to guide an eventual effort to develop a framework to ensure CMHPs sustainably improve health outcomes. A preliminary analysis of results from a community participatory research was done in which baseline health characteristics, related social determinants, level of involvement of CMHPs with the local government health system, and quality of life were documented through surveys, focus group discussions and key informant interviews, both in a community with an established CMHP (Murcia, Negros Occidental, Philippines), and a control area without a similar NGO sector (Isabela, Negros Occidental).
\end{abstract}

Results. There was higher NGO and local government involvement among respondents in Murcia, use of traditional medicine, and sense of awareness of the need to improve the water quality in Murcia, with noted persistence of sanitation concerns, pinpointing the need to assess community participation and the efficiency of CMHPs.

Conclusion. Further study is needed in measuring community participation while considering its underlying cultural and socioeconomic contexts, in order to facilitate planning and implementation of strategies that intend to address community-recognized health needs while sustainably improving health outcomes.

Key Words: community-managed health programs, community participation, health, Philippines

\section{INTRODUCTION}

Corresponding author: Hilton Y. Lam, MHA, PhD Institute of Health Policy and Development Studies National Institutes of Health

University of the Philippines Manila

Taft Ave., Ermita, Manila 1000 Philippines

Telephone:+632 3543832

Email: hylam@up.edu.ph
Community-managed health programs (CMHPs), a form of primary health care (PHC) that emphasizes community empowerment to address underlying causes of disease, were developed in response to the need to build "self-reliance" and "self-determination" in economically disadvantaged communities. ${ }^{1}$ This is in response to the 
1978 Alma Ata Declaration, which advocated "health for all" by defining PHC as "essential," "socially acceptable," and "affordable" health care compatible with scientific standards that is "accessible to individuals and families in the community through their full participation," while "[involving], in addition to the health sector, all related sectors and aspects of national and community development" and "[promoting] community and individual self-reliance and participation in the planning, organization, operation and control of primary health care." ${ }^{2}$ Since its adoption by the World Health Organization (WHO), the concept of $\mathrm{PHC}$ has been implemented in various forms, depending on prevailing socioeconomic, political and cultural contexts.

In the Philippines, there have been attempts from both government and non-government organizations (NGOs) in setting up health care systems that utilize the $\mathrm{PHC}$ approach. These attempts have been categorized into three (3) forms of PHC-influenced community health programs, which differed from one another in terms of the level of control exerted by the community on decision making: community-oriented programs, community-based programs, and community-managed programs. Specifically, community-oriented health programs are mainly run by health professionals with predetermined health objectives. In this set-up, decision making was reserved to health professionals, in consultation with communities, who were treated as "beneficiaries." Meanwhile, community-based health programs treat the community as "partners in health care," and are designed and managed together with health professionals. Decision making in this set-up is shared by the community and the professionals. Finally, CMHPs, touted as "health by the people" are ideally guided by objectives that have been designed by the community, in recognition of its health and socioeconomic needs. In this set-up, community members are the decision makers, and health professionals from outside the community are merely consulted. ${ }^{1}$ The concept of community participation, varyingly pervading these three forms of health programs, became a foundational principle for the local government autonomy that was mandated by the Local Government Code (LGC) in 1991, but these programs have already been put up in many areas in the country even before the 1978 Alma Ata Declaration, when state-implemented public health care services had been mostly carried out in clinics and hospitals. ${ }^{3-5}$

Additionally, since the implementation of local autonomy in accordance with the LGC, health care services have been devolved to local government units (LGUs), with the central government remaining as evaluator of health system performance and provider of technical assistance to LGUs. This devolution was inspired by the community-managed ideal, but with the accompanied risk of exposing health affairs to the control of local politics, which often accepted or even promoted preexisting social inequalities. ${ }^{6}$ It must be noted that the Declaration itself identified social inequity as a root cause of poor community health, in anticipation of the social determinants of health (SDH) framework to be developed decades later, which linked persistent health problems with societal, economic and cultural circumstances of individuals and communities. ${ }^{7,8}$ In view of these systemassociated difficulties in achieving the PHC ideal, CMHPs have been put up by communities, who had been engaged and organized by NGOs. These CMHPs often co-existed harmoniously with the local government health system, but focused on interventions that the community had chosen in response to its unique needs, thereby allowing empowered communities to work towards "health for all" without being institutionally tied to local government politics.

However, with increasing national and global attention to the need for financial risk protection and service delivery networks within health systems, where transactions need to be seamless across venues of health care service delivery, CMHPs must be able to harmonize its operations with a particular standard to gain access to the national health insurance system and the larger health system. This access requires a harmonized approach to financing, health information, and service delivery, and thus necessitates an insightful study of the scope of current CMHP interventions, institutional and community readiness, and points of interface with other health facilities. ${ }^{9}$ These assessments cut across sectoral boundaries, and challenge communities to broker linkages, while also rethinking the way they address their own health needs, and redefine their concept of community participation itself.

With these emerging concerns, CMHPs have come to a crucial crossroad, with the need to adjust to these changes, while still targeting the unique health needs of the communities they serve. These two divergent but nonconflicting issues demonstrate the need to operationally redefine community participation in a way that considers the need to keep track of performance, while aiming for an ideal of "health for all," which remains a multidimensional target that cuts through sociocultural and economic definitions of what it means to achieve health. ${ }^{2}$

Therefore, this study conducted a preliminary analysis of community baseline characteristics and related social determinants of health, and the scope of available health interventions in a community with an established CMHP and NGO sector, and compared it with a control area with a less prominent NGO sector. The level of involvement of CMHPs with the local government health system was also documented. The results of this preliminary study are aimed to guide an eventual effort to develop a framework to ensure CMHPs sustainably improve health outcomes, while involving them with ongoing national strategies for health financing and service delivery networks.

\section{METHODS}

Two areas in Negros Occidental province in the Western Visayas region (Region 6) were chosen as study sites on 
the basis of similar baseline characteristics, but with one of them having a strong CMHP presence. The predominantly rural municipality of Murcia, population 81,286 (2015) with CMHPs catering to multiple barangays (villages) was the intervention area, while the rural municipality of Isabela (2015 population: 62,146) was chosen as control area. Using a participatory research model approved by the University of the Philippines Manila Research Ethics Board, this mixed methods study gathered data through surveys, which were administered both individually (Murcia: 586 respondents, Isabela: 2,852) and by household (Murcia: 252 respondents, Isabela: 1,112). These surveys gathered basic demographic data, educational attainment, sources of income, and information related to health seeking behavior, health services utilization, involvement in local government affairs and civic society organizations, sources of drinking water, sanitation, and waste management. Additional questions for survey respondents in the intervention area gathered information on the level of awareness of the CMHPs' existence. Moreover, questions related to perceived quality of life (i.e. problems in activities of daily living, presence of depression or discomfort) were asked from all participants, along with a list of social issues adversely affecting their way of life, the severity of which they rated from a scale of 1 to 5 , with 5 being most severe. The categories were chosen on the basis of the way of life being led by the people in the two communities, as well as measurable components of the SDH framework, the PHC definition and European Union standards for measuring quality of life, which can be reasonably answered by respondents without discriminating on the basis of educational attainment. ${ }^{2,8,9}$

In addition, to gather qualitative data, focus group discussions (FGDs) and key informant interviews (KIIs) were conducted. Particularly, in Isabela municipality, 17 KIIs were conducted with local officials and other stakeholders, of which three were conducted with municipal officials, six with the officials of Barangay Bulad, three from Barangay Tinongan, three from Barangay Camang-Camang, and two from Barangay Panaquiao. Similarly, for Murcia municipality, the intervention area, $16 \mathrm{KII}$ s were conducted, of which one was conducted with a municipal official, four with officials from Barangay Minoyan, five from Barangay Caliban, three from Barangay Blumentritt, and three from Barangay Damsite. The team also interviewed four provincial officials and one NGO partner. Additional questions for respondents in the intervention area included an inquiry on how the local CMHP was involved with the local government health system. Statistical analysis of quantitative data was done using Stata, with subsequent triangulation and thematic analysis with qualitative data.

\section{RESULTS}

\section{Baseline characteristics}

Respondents from the two municipalities had similar baseline characteristics, with both samples having almost a 1:1 male to female ratio, and are almost all Hiligaynon-speaking and affiliated with the Catholic church. Approximately $60 \%$ of respondents from both municipalities only reached or graduated from elementary school. Meanwhile, 59.13\% of respondents from Murcia reported that they belonged to income class $\mathrm{E}$ (i.e. earning an annual income of less than Php40,000), while $66.55 \%$ reported the same in Isabela. ${ }^{9}$ In terms of the perceived adequacy of their respective incomes, 81.22\% of households surveyed in Murcia felt their incomes inadequate; this was the same for $51.19 \%$ of respondents in Isabela. To generate income, almost $47 \%$ of respondents from Murcia engaged in backyard gardening, while almost the same percentage of respondents from Isabela subjected themselves to the pakyaw system, in which laborers are hired as one group and are paid by a lump sum to be divided among group members.

As regards causes of morbidity and mortality, official health statistics from both municipalities show that the majority of clinical consults were due to diseases of respiratory or infectious origin (influenza, cough, colds, fever, loose bowel movement), with asthma and hypertension accounting between almost 2 to 3\%. Meanwhile, top causes of mortality for both municipalities, ranging from 3\% to $11 \%$ of all registered deaths, were mostly non-communicable diseases (heart disease, stroke, cancer), asthma, tuberculosis, and trauma; but uniquely, Murcia counted diabetes, measles, hepatitis and immunocompromised state ("immune system loss"), each accounting for almost $5 \%$ of all reported deaths, while Isabela included “old age," murder/homicide, and kidney, each comprising between $2 \%$ to $7 \%$ of all registered deaths.

\section{Water, sanitation and environmental health}

Generally, the majority of water sources are non-potable in both municipalities, and in Murcia, are accessed mostly through faucets (36.79\% of participants) or springs (31.07\%), with $16.43 \%$ sourcing water from dug-out wells. This is in comparison with Isabela, in which $50.81 \%$ respondents said they sourced water from a dug-out well, $24.12 \%$ from a deep well, and $14.54 \%$ from a spring. In response to having the majority of its water sources considered non-potable, both municipalities are eyeing to put up programs to improve water access, with Murcia specifically planning to implement the Sagana at Ligtas Na Tubig sa Lahat (Abundant and Safe Water for All, or SalinTubig) project promoted by the Department of Health. Interestingly, in terms of public perception on the potability of water, $64.33 \%$ of Murcia respondents reported that their water was clear, $59.73 \%$ said it was sufficient, and $61.60 \%$ said the water had an agreeable smell and taste; while $80.43 \%$ of Isabela respondents considered their water clear, $79.98 \%$ considered their water supply sufficient, and $79.70 \%$ said that their water had an agreeable smell and taste.

Connected with water sanitation and environmental health is the ability of the municipal governments to enforce the use of sanitary toilets and household water drainage. In Murcia, toilet bowls were used by $77.09 \%$ of the respondents, 
with $4.73 \%$ disposing human waste in the rivers, and the remainder using dug holes or pit privies, practicing open defecation, or using the toilets of other households. Despite the preceding statistics, the public toilets maintained by the local government were perceived to be clean by $67.75 \%$ of respondents, and without flies (71.19\%) but $50.17 \%$ considered them smelly. Meanwhile, in Isabela, $81.9 \%$ of respondents reported use of toilet bowls, and $2.5 \%$ disposed human waste in rivers; while almost $90.0 \%$ of respondents complained that their public toilets were smelly, unclean and infested by flies. Concerning household water drainage, most households from Murcia (48.08\%) and Isabela (52.27\%) dumped their waste water directly into the ground, without leading the drain towards a tank or reservoir. The other sanitary lines that were also widely used included canals, underground pipes, and rivers.

Finally, with regard to waste management, $99.96 \%$ of respondent households in Isabela reported daily collection of garbage. In Murcia, 100\% of respondent households reported a regular garbage collection that was only carried out at most every fourth day. Also, concerning public dumpsites, most of the individual respondents from Isabela (72\%) described these as lacking in space, smelly, and had too much flies. In Murcia, too much flies, bad smell, and lack of space were also observed by $65.21 \%, 66.21 \%$, and $55.80 \%$ of respondents, respectively. Based on the qualitative data collected, the two municipalities did not have an overarching program for waste management, although barangays Minoyan and Damsite in Murcia had ordinances penalizing against those who were not following proper waste disposal management, and some barangays in Isabela had programs regarding garbage segregation and health education.

\section{Health service utilization and health seeking behavior}

Indicators that were chosen to assess health services utilization and health seeking behavior include adherence to immunization schedules, deworming rates, choice of first intervention upon onset of clinical symptoms, choice of health professional or healer for first consult of a clinical complaint, and the use of traditional medicine practices. These results should be contextualized with the limited health human resources of the local health systems. In Murcia, one doctor, one rural sanitary inspector (RSIs), one medical technologist and one dentist serve in the local government health system, supported by 17 nurses, and 30 midwives, along with 75 traditional healers. Meanwhile, in Isabela, one doctor, one medical technologist, and one dentist serve the local health system, supported by two nurses, 20 midwives, and two RSIs.

While both municipalities were comparable in adherence to immunization and deworming, significant difference was seen in the choice of health intervention upon onset of clinical complaints. More respondents from Murcia used home remedies such as herbal medicines (70.82\%), bilot (Filipino traditional massage) and ventosa (cupping therapy) (5.21\%) compared to those from Isabela (20.56\% and $1.40 \%$, respectively). Murcia respondents were also more likely to avail of treatment at home $(83.01 \%$ versus $58.66 \%$ in Isabela) or seek the assistance of family members (75.07\% in Murcia versus $57.01 \%$ in Isabela). These efforts often result to improvement of symptoms (96.99\% in Murcia versus $93.36 \%$ in Isabela). It is likewise of interest that there were more households in Murcia $(76.98 \%$ and $73.81 \%)$ compared to Isabela (66.28\% and 55.22\%) that had backyard vegetable gardens and medicinal gardens. It is also noteworthy to mention that all health services in Isabela are offered by the health system run by the local government, but qualitative data yielded information that the facilities were often insufficiently staffed, experienced stock outs, and were relatively hard to access via conventional transportation.

\section{Community involvement indicators}

Community involvement in both municipalities was assessed by looking at their level of participation in civic society organizations and in the affairs of local government. Majority of respondents from Murcia and Isabela reported that they were willing to contribute to the development of their respective communities. Some of their reasons, based from the qualitative data, were the following: the spirit of bayaniban (cooperative endeavor) within the communities, empathy, the desire to share their knowledge and experiences, and the desire to be involved in good governance.

Organizations and government programs that encouraged empowerment in both municipalities were senior citizens' and women's organizations, the Kapit-Bisig Laban sa Kabirapan (Arm-in-Arm Against Poverty) - Comprehensive Integrated Delivery of Social Services program of the Department of Social Welfare and Development (DSWD), Negros Occidental Rehabilitation Foundation Inc., and the Pantawid Pamilyang Pilipino Program (4Ps, the national conditional cash transfer program for indigent households) as mentioned by the participants of the FGDs and KIIs. In Isabela, only $26.44 \%$ of individual respondents were involved in these organizations. Additional organizations present only in Murcia, where 43\% of respondents were involved in such groups, were health-oriented organizations involved in the CMHPs, QuidanKaisahan, the Catholic Social Action Center, SUMAKAWI Farmers Association, and the Integrative Medicine for Alternative Healthcare Systems (INAM) Philippines, Inc.

Meanwhile, regarding involvement in local government affairs, most respondents from Isabela participated in the promotion of ordinances (93.99\%), barangay assemblies (90.84\%), financial contribution (86.87\%), and availed of free or affordable services offered by local government (81.31\%). In Murcia, the percentages were higher in terms of the promotion of ordinances (98.63\%), financial contribution (98.12\%), barangay assemblies (97.61\%), and availment of free or affordable services (88.89\%). Qualitatively, mechanisms for participation in Murcia were more open, thus encouraging 
people to freely participate in addressing their respective barangays' concerns and health.

\section{CMHP-related indicators}

In gauging the impact of the CMHPs in Murcia, the team assessed their awareness of services offered by the CMHPs, and qualitatively inquired on how the CMHPs are involved in local government affairs. While Murcia's local government health system still provided immunization services, medical consultation, home visits, medicines and a mental health program, CMHPs within its jurisdiction provided health education and support for herbal gardening. These efforts were fairly known by Murcia respondents, with $80.36 \%$ being aware of the CMHPs' support for herbal gardening, and $63.91 \%$ for their health education program. However, lesser known among the services offered by the CMHP are home visits (26.32\%), its own mental health program (21.28\%), provision of medicines (15.74\%), medical consultation (11.78\%) and immunization (1.29\%). Furthermore, CMHPs were involved in local government affairs through integration into the local health system referral network, advocacy and lobbying on behalf of community interests for the passage of health and development-oriented ordinances, and aiding the local health authorities to enforce rules on cleanliness, sanitation, potable water sources and the zero open defecation policy.

\section{Quality of life and social issues}

With the assumption that a general sense of well-being is also affected by prevailing social issues and quality of life, individual respondents from both municipalities were asked to identify and rate the top most severe community issues in their municipalities, identify any difficulties in ambulation, washing or dressing oneself, and activities of daily living; and report the presence of any form of discomfort, pain, anxiety or depression. ${ }^{8,10}$ As identified in Table 1, both municipalities identified drug addiction, alcohol intake, smoking, and gambling, followed by pollution, crime, and housing problems as social issues of deep concern to them. Meanwhile, most of those from Murcia (91.81\%) and Isabela (75.61\%) had no problems in walking, in washing or dressing themselves (96.76\%, 90.95\% respectively), and in doing their usual activities $(95.56 \%, 81.96 \%)$. Additionally, most of those from Murcia (93.69\%) and Isabela (71.33\%) had not been experiencing any pain or discomfort, while $96.25 \%$ of respondents from Murcia and $79.16 \%$ from Isabela did not report being anxious nor depressed.

\section{DISCUSSION}

The effort to measure the magnitude of health and social concerns in the context of comparing communities with and without CMHPs is, to our knowledge, the first to be documented in scientific literature. The differences between the two municipalities in terms of health and social involvement indicators, and the context behind these differences are noteworthy, and hint at a possible relationship between better health outcomes and community empowerment, which is apparently demonstrated by the increased NGO involvement of locals in Murcia, the communal desire to make use of locally available herbal remedies and traditional practices before consulting health professionals in the spirit of self-reliance, and the choice of livelihood (the preference of engaging in backyard gardening in Murcia versus the tendency include oneself in the pakyaw system in Isabela).,212 Other manifestations include an increased sense of awareness of the need to improve the water quality in Murcia, and the increased level of participation in local government, especially in assemblies that aim to inform the public and generate insights about issues that are important to the local legislature. ${ }^{12}$ The relatively widespread awareness of the preventive aspect of CMHP presence in Murcia, in contrast to a possible identification with curative services that are the responsibility of the local health system, is also reassuring, and suggests that the CMHPs are considered an integral component for achieving long-term improvement of health status in the municipality. This is in addition to a clear delineation of responsibilities between the CMHPs and the local health system, which has been effectively communicated to locals, as evinced by how well the majority of respondents correctly identified the services that can be availed in CMHPs and in the local health facilities, and thus, a manifestation of how well the CMHPs penetrated the social consciousness, which has been shown as a success factor for health programs. ${ }^{13}$

Nonetheless, to present a more compelling argument in support of CMHPs and their positive health and social impact on communities, there is a need for a retrospective analysis of baseline health and social conditions in host municipalities before the creation of CMHPs, and an assessment of the efficiency of CMHP operations, which were not done and are thus important limitations of this study. Another noteworthy limitation of this study was the inability to assess the capacity of CMHPs (and indeed, local government as well) to aid citizens in health-related expenses, a need that was made apparent by the poverty prevalence of both municipalities.

Table 1. Top Community Concerns in Terms of Severity According to the Respondents from Murcia and Isabela, Negros Occidental

\begin{tabular}{|c|c|c|c|c|c|}
\hline \multirow{3}{*}{ Rank } & \multirow{3}{*}{ Issue } & \multicolumn{4}{|c|}{ Total Degree of Severity } \\
\hline & & \multicolumn{2}{|c|}{ Murcia } & \multicolumn{2}{|c|}{ Isabela } \\
\hline & & Frequency & Percentage & Frequency & Percentage \\
\hline 1 & Drug addiction, alcohol intake, smoking, gambling & 1,072 & $20.0 \%$ & 6,299 & $21.8 \%$ \\
\hline 2 & Pollution & 959 & $17.9 \%$ & 4,298 & $14.8 \%$ \\
\hline 3 & Crime & 838 & $15.6 \%$ & 4,181 & $14.4 \%$ \\
\hline 4 & Housing problem & 650 & $12.1 \%$ & 3,584 & $12.4 \%$ \\
\hline
\end{tabular}


Another issue that deserves mention is how these CMHPs, already enjoying a significant level of buy-in from the community, can accommodate impending national health system changes, especially as regards health financing and health information. Though referral networks and a harmonious relationship with local government were mentioned in the results, there remains a need for assessing the ability of CMHPs to continue addressing preventive health aspects while adopting and adjusting to the national health financing strategy and the drive towards strengthening service delivery networks, which were defined by the Department of Health as "[a] network of health facilities and providers within the province- or city-wide health system, offering core packages of health care services in an integrated and coordinated manner." 9

CMHPs may have been designed for communities to take charge in resolving underlying causes of health problems, following the spirit of the 1978 Alma Ata Declaration, but also, by mentioning concepts of "scientifically sound health care" within a "New International Economic Order," the 1978 Alma Ata Declaration implicitly required that health programs should generate better health outcomes; and hinted the need to partner with or hire professionals who can provide necessary scientific guidance for health interventions in keeping with global health standards and to attain ideal health indicators. ${ }^{2}$ Analyzing the results of this preliminary results leads to an observation that despite a strong CMHP sector in Murcia, health issues remain, the most important of which being sanitation and environmental health. These are issues that notoriously cut across sectoral boundaries, which in the local context, require a concerted effort to engage with government, thus requiring interventions that are reliant on community participation. ${ }^{14,15}$ Planning these interventions while considering the need for sustainability and social acceptability for efficiency, and generating better health outcomes thus requires an ability to measure community participation itself. ${ }^{12,13,17,18}$

Unfortunately, not many studies on measuring community participation in the context of achieving better health outcomes have been carried out globally. Nonetheless, one study done on this topic provides insight on how community participation in health programs can be assessed, in order to ensure that CMHPs attain better health outcomes. In a review by Draper, Hewitt, and Rifkin, five indicators were proposed, the use of which was successfully replicated in Ghana by Baatiema and colleagues, to wit:

1. Leadership of the community and of the professionals introducing the interventions,

2. Planning and management forging partnerships between community and professionals,

3. Women's involvement,

4. External support for program development in terms of finance and program design, and

5. Monitoring and evaluation examining how intended beneficiaries are involved in program activities. ${ }^{15,17,18}$
Therefore, future directions of this ongoing participatory research should include a deeper analysis of these five indicators, while also investigating issues that underlie the persistence of health concerns in Murcia, and gleaning experiences from the CMHP experience therein for eventual implementation in Isabela, in areas with CMHPs, and in other areas with persistent health problems.

\section{CONCLUSION}

Despite the promising preliminary results of this participatory research, in which the direct relationship between CMHPs and health outcomes is suggested, further study is needed in measuring community participation while considering its underlying cultural and socioeconomic contexts, in order to facilitate planning and implementation of strategies that intend to address community-recognized health needs while sustainably improving health outcomes.

\section{Acknowledgments}

The research team gratefully acknowledges the participating communities, and the assistance of Jeffrey L. Flores, Jesson James A. Montealto, and Maria Fatima A. Villena in preparing this manuscript.

\section{Statement of Authorship}

All authors approved the final version submitted.

\section{Author Disclosure}

All authors declared no conflict of interest.

\section{Funding Source}

This work was supported by the University of the Philippines Emerging Interdisciplinary Research Program under the Office of the Vice President for Academic Affairs under Grant C3-007.

\section{REFERENCES}

1. Galvez Tan J. Primary health care in hands of the people. In: Book of readings on Primary Health Care. College of Public Administration, University of the Philippines, Diliman; 1996. pp. 1-15.

2. World Health Organization (WHO), Declaration of Alma-Ata [Online]. 1978 [cited 2016 Dec]. Available from http://www.who.int/ publications/almaata_declaration_en.pdf?ua $=1$.

3. Grundy J, Healy V, Gorgolon L, Sandig E. Overview of devolution of health services in the Philippines. Rural Remote Health. 2003; 3(2):220.

4. Morgan LS. Community development: observation around the world. Am J Public Health Nations Health. 1965; 55(4):607-12.

5. Roemer MI. Political ideology and health care: hospital patterns in the Philippines and Cuba. Int J Health Serv. 1973; 3(3):487-92. doi:10.2190/F1LQ-VFD5-U33C-QW7Q.

6. Bossert TJ, Beauvais JC. Decentralization of health systems in Ghana, Zambia, Uganda and the Philippines: a comparative analysis of decision space. Health Policy Plan. 2002; 17(1):14-31.

7. World Health Organization. Social determinants of health [Online]. 2015 [cited 2016 Feb]. Available from http://www.who.int/social_ determinants/en/. 
8. Solar O, Irwin A. A conceptual framework for action on the social determinants of health. Social determinants of health discussion paper 2 (policy and practice) [Online]. 2010 [cited 2017 Aug]. Available from http://www.who.int/sdhconference/resources/ ConceptualFrameworkForActiononSDH_eng.pdf.

9. Department of Health (DOH). Guidelines in establishing service delivery network [Online]. 2017 [cited 2017 Aug]. Available from http://www.doh.gov.ph/sites/default/files/publications/Guidelines \%20EstablishingSDN.pdf.

10. European Union. Quality of life indicators [Online]. 2017 [cited 2017 Aug]. Available from http://ec.europa.eu/eurostat/statistics-explained/ index.php/Quality_of_life_indicators.

11. Philippine Statistics Authority (PSA). Distribution of families by income class, by Main Source of Income and by Region [Online]. 2015 [cited 2017 Aug]. Available from https://psa.gov.ph/sites/default/ files/attachments/hsd/article/TABLE\%208\%20Distribution\%20 of $\% 20$ Families\%20by\%20Income $\% 20$ Class\%2C\%20by\%20Main\%20 Source\%20of\%20Income\%20and\%20by\%20Region\%202015.pdf.

12. Laverack G. Improving health outcomes through community empowerment: a review of the literature. J Health Popul Nutr. 2006; 24(1):113-20.

13. Merzel C, D'Afflitti J. Reconsidering community-based health promotion: promise, performance and potential. Am J Public Health. 2003; 93(4):557-74.
14. Graham H, White PC. Social determinants and lifestyles: integrating environmental and public health perspectives. Public Health. 2016; 141:270-8. doi:10.1016/j.puhe.2016.09.019.

15. Labonté R, Sanders D, Packer C, Schaay N. Is the Alma Ata vision of comprehensive primary health care viable? Findings from an international project. Glob Health Action. 2014; 7(1):24997. doi:10.3402/gha.v7.24997.

16. Shediac-Rizkallah MC, Bone LR. Planning for the sustainability of community-based health programs: conceptual frameworks and future directions for research, practice and policy. Health Educ Res. 1998; 13(1):87-108.

17. Draper AK, Hewitt G, Rifkin S. Chasing the dragon: Developing indicators for the assessment of community participation in health programmes. Soc Sci Med. 2010; 71(6):1102-9. doi:10.1016/j. socscimed.2010.05.016.

18. Baatiema L, Skovdal M, Rifkin S, Campbell C. Assessing participation in a community-based health planning and services programme in Ghana. BMC Health Serv Res. 2013; 13:233. doi:10.1186/14726963-13-233.

\section{Have you read the current trends in} Medical and Health Research in the Philippines?

\section{Acta Medica Philippina The National Health Science Journal}

Now available for free at the Apple app store and Google play store.

Available on the

App Store

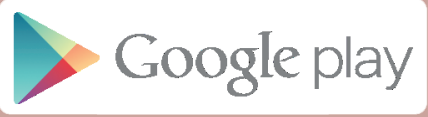

